\title{
Castoriadis and Cognitive Linguistics: A Research Trajectory in the Form of 12 Busy Fragments
}

\author{
by Stephen Hastings-King
}

Having on recent occasions come to grips with the nature of structure, let us take the next step to higher proportion. This does not mean that we have abandoned the realm of structure, for we shall never skip this stage of the initial organization of matter. Structure is not a bridge that is no longer needed once one has gained the farther shore. It is an act of material forming that proves its effectiveness as such beside the larger articulations and adapting its character anew in various parts, accented more or less, interrupted when the context demands it, only to be resumed once again. .1$]$

If there is a problem with Castoriadis' work, it is that few know about it. In the United States, any number of factors may explain the superficiality of reception, from the way in which Castoriadis' work moves across genres to the institutional configuration that has monopolized "French Theory" to the radical consequences entailed by his work for existing modes of information definition and organization. Whatever the explanation, Castoriadis remains a shadow. The aim of this short précis of research possibilities---which is more an outline of my own research trajectory---is that it be set alongside others to encourage the production of new and different types of work.

1. The main paper I made for this journal is an extended argument for the migration of partial-determinist assumptions into the register of the form of analysis. It develops one sequence of possibilities which follow from this, which are linked to the thematic motif built around the play of the instituted and the instituting. From this follows a second-order problem: how to think the pivot term, the noun institution. Cutting across this are traces of a central preoccupation of mine, which centers on the relation of location to sound, which in a way doubles the relation of the instituted to the instituting, the past to the present, object to time.

I refer to the ontological framework that Castoriadis developed in the context of his philosophical writing as partial-determinacy. From my initial encounters with his work that this frame had significant implications for not only how one understands the social-historical, but also for how one refers to it. I designed my earlier work around this, but found that I was limited by the mode of analysis in the exploration of these possibilities. Mine has been a circuitous path toward both figuring out ways to make these implications operative and finding space for my own voice.

What I know is that partial-determinacy as an ontology alters one's relation to the operations of sentences, and in so doing reframes their effects. I understand not 
because I have written this sentence or others like it many times, but because I spent much of the past decade adapting something of Castoriadis work in the context of experimental music. [2] What I know is that partial-determinacy as an ontology alters one's relation to the operations of sentences, and in so doing reframes their effects. It follows that texts should be produced which themselves reframe relations to sentences. This is the basic requirement I impose on myself to experiment with form.

Opening up form opens up space for the production of in-between phenomena that remain in-between phenomena.

2. Most analytic writing tends to reproduce as if natural particular conventions as to scale and perspective. The reader is in the position of the camera in an Americanstyle scientific documentary. When I was young, I would watch on television "Mutual of Omaha's Wild Kingdom" in the context of which the viewer, along with the camera, would stand safe behind a rock while Jim, a burly man dressed in khaki, would wrestle snakes or alligators at the edge of a swamp. Throughout, a narrator would tell you what you were seeing. At the end of each sequence, the camera that watched the camera would pull back and reveal the narrator standing next to a television monitors. Your double was a dapper gentleman who sported the silver hair of adventure and a pencil moustache. He would tell you that what you just saw was quite dangerous and so was everything else perhaps you should consider life insurance.

As Brigitte Fontaine tells us, the $19^{\text {th }}$ century is over.

3. Contemporary politics presupposes and builds upon the convergence of ideology with spectatorship. The skull-bound I interacts (verb) with the world which is staged as an accumulation of objects the meanings of which inhere in themselves. Politics is the fact of their arrangement. The space given along with arrangement is a container. Determinate beings are available to the spectator. Meanings are found, not made.

Relations between phenomena are also relations to them. In Castoriadis' terminology, social-imaginary significations condition the production of surfaces: the surfaces which are co-terminus with relations between phenomena; the surfaces which are coterminous with relations to phenomena. These surfaces are effects of how one thinks through or about the performance of relationality and what constrains it. The project of autonomy leans on a view of these surfaces as the effect of performance, of a form of doing. Spectatorship processes them as given.

Recent work in cognitive linguistics rolls these underpinnings for the production of surfaces into the registers of (embodied) neural networks which unfold/condition each other in response to perturbations within the umwelt, the physico-electrical environment through which we move and to which we continually adjust.[3] Rolling signification into a space shaped by neurological functions reduces the range of actions which are amenable to unproblematic reflexivity, increasing that of 
automatism and repetition on the one hand and emphasizing the importance of phronesis on the other.

Work in neurolinguistics is conditioned implicitly by the assumption that the subject is one thing, language is one thing and ideology a different thing. Castoriadis' discourse of the social imaginary makes these separations impossible to maintain.

4. The instituting as an unavoidable dimension of social being brings with it practice or process, which brings with it embodiment, motion, temporal being. [4]

The more precisely the position is determined, the less precisely momentum is known and vice-versa. $[5]$

Heisenberg's is not a statement of uncertainty: it is a statement about measurement. Measurement brings into a type of determination in the context of a particular scale and within a particular pattern of inference. Implicitly, it is a statement about partial-determinacy.

The shift away from Euclidian geometry, with its focus on the construction of objects and the position of elements in the context of constructed objects, was affected through a shift of focus from away from objects as given and to the relations which objects presuppose, which comprise them.

Measure determinations require that quantity should be independent of position, which may happen in a variety of ways. The hypothesis which first presents itself (...) is that according to which the length of lines is independent of their position and consequently every line is measurable by means of every other.[6]

This shift in emphasis did not immediately result in the articulation of non-Euclidian analyses and still less of the types of "space" entailed by them. These were worked out procedurally and collectively. Tying the form of analysis directly to what is being analyzed, the exploration of ways to link the instituted and instituting, the integration of research into various modalities of grouping constitute procedures for articulating analytic direction. The spaces which are entailed are themselves territories for recursive interrogation.

Each of these is a particle:

A particle in other words must be shaped in such a way as to lend itself to movement and conduction. For particles have no separate existence, merely serving in support of larger functions. A particle subserves some higher-order process that is capable of further development. A particle subserves some higher order which it transmits in several directions over into three dimensions. [7]

4 Frame The convergence of cognitive neuroscience and linguistics derives from writing by George Lakoff. Particularly influential is his theory of "pre-conceptual structures," the "directly meaningful concepts" or categories that are the conditions of possibility of experience. Lakoff distinguishes "basic-level" and "image-schema" 
structures. Basic-level structures arise "as a result of our capacities for gestalt perception, mental imagery, and motor movement" and manifest through categories such as hunger and pain, water, wood, and stone, people and cats. Image-schemas are spatial mappings such as source-path-goal, center-periphery, and container.[8] In Lakoff, these pre-conceptual structures are staged as trans-cultural, as "fixed points" which enable "the objective evaluation of situations." It is not at all obvious that this is the case. [9]

The basic idea builds on work in developmental psychology which originated with Piaget and A.M. Luria, who outlined from differing angles something of the centrality of language acquisition to the formation of the institution of the "I." Language comprises the basis for the organization of memory and so of memory itself, which is the condition of possibility for the emergence of the space of the I, the sense of it's separateness from the environment. The sense of discreteness or separateness is in turn the condition of possibility for being able to act independently (and not just mimetically) on the environment. The creation of memory through its organization is also a rearticulation of the senses and the hierarchies which obtain within and amongst them. $[10]$ From a Piagetian viewpoint, it is obvious that a significant "hardwired" component underpins and enables these transformations. However, Piaget's view of human development moves from sequences which are more dominated by the unfolding of hardwired schemata to those which are less so, as if the space of freedom and ethical action required it. ${ }^{[11]}$ The overall movement is from constraint to independence, a trajectory that would lead one to imagine the intertwining of neural pathways and linguistic structures and particles is dominant during an earlier phase of development, but fades over time.[12]

Cognitive linguistic research adapts the notion and relative position of "preconceptual structures" from Lakoff along with the starting-point of a functional adult subject. These become a typology which serves to orient theorizing neural network functionalities. While this area of research uses a traditional point of departure (in the adult functional subject taken both as given and as generalizable), it is in other areas most innovative. To begin with, this work breaks with the earlier tradition within cognitive linguistics $[13]$ :

The propositional picture of mind conveyed by early cognitivism is that of a functional system whose processes can be described in terms of manipulations of abstract symbols according to a set of formal syntactic rules (...) We shall present a very different view. We will argue that conceptual knowledge is embodied, that is, mapped within out sensory-motor system. We will argue that the sensory-motor system not only provides structure to conceptual content, but also characterizes the semantic content of concepts in terms of the way we function within our bodies in the world. Before delving deeply into the argument, we should discuss a major finding in neuroscience that we will be assuming throughout: Imagining and doing use a shared neural substrate.[14]

Embodied conceptions of language open onto thinking language usage in time as fundamental to the processes of auto-figuration. This shift entails another, from 
language as a self-enclosed system interaction with which can be understood on the basis of symbolic or logical analyses to a more open-ended conception in amenable to being though across the dynamic of the instituted and instituting.

5. Frame $+\mathbf{1}$ Acknowledging the instituting entails a break with the assumption of symmetry. ${ }^{[15]}$ One imagines spin as symmetrical in the context of 3 -space: if a particle is put into motion in this way, it follows that the movement would be more or less the same when viewed from any angle. Kinematic motion involves a dimensional shift and a phenomenon referred to below as "reflection":

The hyper-number i needs only a plane for visualization because, as it is multiplied by itself, it rotates in a plane as does a unit radius when a circle is drawn. But the hypernumber $\dot{\varepsilon}$ involved reflection...It is clear that in order to turn a right hand into its reflected version (a left hand), more is required than sliding or rotation in tridimensional space. It can be shown that a right hand would change into a left hand if it were rotated $180^{\circ}$ out of our triple-dimensional space into a four-dimensional space and then back into our space again....Therefore because $\dot{\varepsilon}$ deals with reflections and not only with simple rotations as does $i$, its operates demand geometrically a four-dimensional spaces, whereas the simple rotational character of $i$ 's operations demands only two-dimensional space.

In this book Enlightenment to Enlightenment, Henri Atlan discusses at some length the centrality of assumptions which are imported from the frame of reference of the investigator in creating problems or limitations in the investigation. Examples of this include the assumption that each scale of analysis is discrete, which creates (rather than reproduces) problems of integration of scales and the assumption that a whole can be understood by decomposing it into parts, which creates (rather than reproduces) problems for thinking macro-level behaviors in complex biological systems for which emergence is a fundamental dimension.

Such mappings link to the assumption that the determinacy, inscribed in the context of the ensidique, enables a complete description of being. Consistent of the substitution of the instituted for the instituting this presupposes, such a view shears off the poeitic.

6. Frame -1 Complex dynamical systems modeling does not work with a complete map of neural networks in relation to specific modalities of brain functioning. Rather it develops approaches to embodied cognition based on modeling procedures that treat as points of departure assumptions about complexity, chaos theory, and temporal being:

Natural cognitive systems are enormously subtle and complex entities in constant interaction with their environments. It is the central conjecture of the Dynamical Hypothesis that these systems constitute single, unified dynamical systems. This conjecture provides a general theoretical orientation for dynamicists in cognitive 
science, but it has not been (and may never be) demonstrated in detail, for nobody has specified the relevant magnitudes, phase space, and rules for evolution for the entire system. Like scientists confronting the physical universe as a whole, dynamicists in cognitive science strive to isolate particular aspects of the complex, interactive totality that are relatively self-contained and which can be described mathematically. Thus in practices, the Dynamical Hypothesis reduces to a series of more specific assertions to the effect that particular aspects of cognition are the behavior of distinct, more localized systems. ${ }^{[17]}$

Because of the fragmentary understanding of dynamical systems, there is a tendency within the literature to look to philosophy for in heuristics that might facilitate the imagining of an overarching system. Several such projects have turned to MerleauPonty, particularly to the notions of embodied cognition outlined in the Phenomenology of Perception. Merleau-Ponty's descriptions of embodiment begin with an abstract subject which finds itself embedded within a world. 18$]$ Mapping this into the operation of contemporary scientific investigation in turn enables work to retain the embodied subject as a type of object, the characteristics of which are all simultaneously present, even as it is a peculiar kind of object which is inclined to engage in a continuous dance with its environment, casting schemata as Oskar Schlemmer choreography casts lines and spirals about the space of the stage.

7. Interior Within the space of symbolic operations, work on linguistic categorization in psychology had put categories into motion and in the process shifted focus away from the meaning to the ways in which they are used. In most such work, "category" is expanded to include any mode of grouping information which can be articulated verbally. For example, Lawrence Barsalou interrogated operative notions of "typicalness" and derived from the results a theory of conceptual "gradation." The experiments developed by his research group presuppose Wittgenstein's notion of family resemblance, but attempt to isolate operationally salient features that can account for similarity as an action rather than as an effect of symbolic organization. The problem is circularity. This is a rake: what characterizes a rake and why do you associate these characteristics with a rake?

Barsalou isolates three modalities of pattern generation. Each type involves a specific organizing node that recapitulates the conditions or relations that distinguish one type from another. The types are: central tendencies (which subset of a range of possible referents are understood to be emblematic of the range); ideals (the normative association which are more operational in goal-directed activities); and frequency of instantiation. "Central tendencies" involve a verbal category directly, or repeat the relation of looking at an object or set of objects. Ideals emerge from within goal-directed activities and amount to schemata that recapitulate aspects of the broader project of which they are parts (for example "things to take on a camping trip"). Frequency is a function of familiarity, which in turn points to the centrality of being embedded within a particular social-historical context. This analytic trajectory reveals such considerable variation in "typicality" categories become "theories about the world" that emerge from and refer back to one's sociocultural milieu. ${ }^{[19]}$ The problem is that the analytic emphasis is misplaced, shifting 
away from the operation of bringing phenomena into relation as a process of making meaning to an understanding of it as a kind of application.

8. This earlier work in conceptual coherence and that done by neurologically oriented researchers are looking for the same thing: the underlying structures which explain the role of pattern as condensed onto language in the institution of a perceptual reality. With the shift out of the assumption that to analyze interactions with language is necessarily to actions performed upon symbols, cognitive linguistics since Lakoff has not only opened interrogation of being-through language also altered the operative time-frame. Being-through language and the space of time consciousness in the phenomenological tradition begin to converge.

However, despite the interest and complications posed by this change of time-frame, it is not obvious that cognitive linguistics does more than displace the circular relationships outlined with reference to Barsalou: between the instituted and instituting at the level of how categories allow for the grouping and/or processing of information in "real time"; between the instituted ways of grouping information in particular and the social-historical embeddedness of a given population in general. Both loops surface in the relation between attractors and neural patterns.

Recent cognitive linguistics then transposes Lakoff's thesis concerning underlying preconceptual structures into the space of complex dynamical systems modeling of neural networks. The assumptions which shape this work in general are that the perceptual field is an emergent property. Perturbations in the environment present themselves as attractors which trigger an ad-hoc recognition and shaping through the activation of pre-conceptual structures. These structures are the interpenetration of linguistic elements and types of physical movement/muscle memory linked by patterns of neural activity. In complex dynamical systems models, a level of apprehension and forming of information is performed in a register of electrical activity that includes bodily movement and cognitive activity traditionally understood within its expanded field. This extends aspects of cognition beyond what Francesco Varela called skull-boundedness and positions it in the interzone between one's physical body and the contexts through which that body moves.

Attractors do not occur in isolation-the theory goes that neural networks generate waveforms which couple and translate information into a form that is amenable to apprehension at an intentional level. The logic here is basically one of coupling oscillators. Two oscillators left running in proximity one to the other will couple, that is they will produce a third waveform that is not the sum of it's parts and which is more stable than either of the two initial waveforms. While much is still not known about how this process works and what its relation is to more traditionally understood sensory arrangements, it is a provocative and interesting direction of research. What the central claim amounts to is that being-through language unfolds in what amounts to an alternate dimensioning of social being which is presupposed by but invisible to the dimensioning of experience with and through language that operates on the results. 
9. Most neurolinguistic research has focused on the elementary grammatical and lexical building blocks of language. Jean Petitot for example develops complex topological models using softwares that array and weight attractors, define trajectories and generate surfaces. These attractors are weighted using transposed data concerning the visual or kinetic modality of embodied cognition under consideration. This idea is to map something of the types of patterning, phase states and modes of dissipation of neural networks as a way of describing the dynamics of this pre-cognitive activity. [20] The basic idea is that these networks should be understood as oscillators which couple. [21]

The problem and appeal of this cognitive neurolinguistic approach mirrors that outlined by Curtis Roads in his description of working with microsound, an approach to building sonic environments using software platforms which enable the isolation of temporal units that hover around the minimum 200 millisecond duration required for audio perception:

Microvariations melt the frozen abstractions of traditional music theory such as continuous tone, pitch, instrument timbre, dynamic marking and even event duration, reducing them to a constantly evolving stream of particle morphologies. Intervals may emerge, but they are not an indispensable grid. There is rather an interplay between intervallic and non-intervallic material.

Within these flowing structures, the quality of particle density---which determines the transparency of the material---takes on prime importance.[22]

If you listen to a Curtis Roads piece on a conventional sound system, without an audio software that would enable you to look at the often quite lovely sculptures made of grains of sound as they pass (an exercise which adjusts your scale of audition to that of the making of the piece), the elements disappear into the cumulative effect of the entire duration. An intricate second will be heard as a curious wobble in an uneven surface. So it is with elaborate models of the patterns which obtain for directional pre-cognitive structures in themselves, despite their potential interest for thinking about the intertwining of linguistic and visual processes more broadly.

10. Any account of this register of social being is necessarily a modeling. Alfred Schutz's comments concerning Husserl's work on time consciousness obtain for cognitive linguistics as well:

Indeed when I immerse myself in my stream of consciousness, in my duration, I do not find any clearly differentiated experiences at all. At one moment an experience waxes, then it wanes. Meanwhile something new grows out of what was something old and then gives place to something still newer. I cannot distinguish between the Now and the Earlier, between the later Now and the Now that just has been, except that I know that what has just been is different from what now is. For I experience my duration as a uni-directional, irreversible stream and find that between a moment ago and just now I have grown older. But I cannot become aware of this while still immersed in the stream. As long as my whole consciousness remains uni-directional 
and irreversible, I am unaware either of my own growing older or of any differences between past and present. The very awareness of the stream of duration presupposes a turning-back against the stream, a special kind of attitude toward that stream, a "reflection."[23]

11. The most striking imagery within complex dynamical systems is that of emergence: any given visual field is an emergent feature of the unfolding, coupling and decay of neural activity. This activity is shaped by both a type of recognition that involves a being-through language linked neurologically to patterns of physical movement. However, insofar as the project of autonomy is concerned, emergence is not in itself the central issue. The work of Henri Atlan and his collaborators on cellular automata demonstrates emergence is characteristic of the self-organization of even relatively simple systems, and results in the coming-into-being of intention-like organization without any necessary connection to volition or consciousness. [24] Emergence is a metaphor across which the play of the instituted and the instituting, mediated by social-imaginary significations, opens onto the project of autonomy by enabling an expanded sense of the degree to which we create what we experience. Emergence is also a way of thinking constraints.

The nature and sources of the basic structures that underpin the emergence of perceptual data amenable to intentional organization opens onto the relation of automatism and repetition to basic ideological relations. Cognitive neuroscience is unlikely to provide much direct insight into this relation. As a function of the genre rules which delimit scientific investigation, work proceeds as if the embodied subject was one thing, language another thing and ideology yet another. Partial determinacy entails the undermining of such separations and the shift into higher levels of abstraction in order to situate these elements in terms of ongoing figurational processes. A dialogue between work that departs from Castoriadis and complex dynamical systems could produce an alternate conception of ideology that would foreground automatism and repetition as central to heteronomy. This is a direction I am considering for a future project.

12. Embodied cognition entails a reconsideration of the model of time consciousness developed within the phenomenological tradition. For example, if at least some of the grouping which Husserl attributed to inferences based on adumbrations (partial views of object-like formations) are performed in and through the emergence of a perceptual field on the basis of neurological functions, Husserl's descriptions of the inferential building-up of coherent phenomena on the basis of series of partial views of "object-like formations" has to be rethought. Similarly, embodied cognition would create problems for the status and roles of retention and protention as well, simply because they, like Husserl's schema itself, are ways of accounting for time consciousness which was staged across a model that limited it mostly within the boundaries of the skull. Bringing neural phasing into consideration of experiential time enables a rethinking the basis for temporal experience by linking it to the displaced traces of the operation of the neural system. This moves questions of accounting for time more generally close to the terrain outlined by Alfred North Whitehead in his 1919 Tanner Lectures on "The Concept of Nature."[25] 
If this work on complex dynamical systems and cognitive linguistics were brought into a conversation with that of Castoriadis, several interesting consequences would follow. First, Castoriadis would made problematic the starting point for much of this work, which takes an abstract adult as it's point of departure to the virtual exclusion of it's processes of socialization and the social-historical contexts which shape it. More broadly, reprocessing the results of these investigations through a partialdeterminist ontological framework would radicalize them by integrating the interior frame of the instituted and instituting, the ensidique and poiesis. The ontological frame might enable a more direct and systematic confrontation with frame-effects, on the order of symmetry and other, related phenomena outlined by Atlan, which are unconsciously mapped into the assumptions that shape investigation. The main tension would probably be rhetorical: Castoriadis' writing operates through a movement which links the social-historical to institutions within it to the space of signification by way of elaborating dynamics that link the general to the particular. This can be broken up to assimilate more finely-grained analytic work, but this breaking up requires that one recode the language to push it through the space of social cognition (which would be the register that the rhetorical and analytic register Castoriadis develops would be understood as, were the ontology stripped away from it) in order to move back into it.[26]

This interests me as an aspect of the problem of how to represent the social-historical in ways that can effect change as they describe, or move through, particular situations. Within that, the interaction between cognitive linguistics and Castoriadis has implications for how one thinks ideology and by extension what one means by its performance, both during phases of ascendancy and, in particular, phases of implosion or disintegration.

[1] Paul Klee: Notebooks vol. 2 p. 69.

[2] The shameless self-promotion footnote: www.clairaudient.org.

$[3]$ The direction I outline here as a research trajectory began with and loops back to Francesco Varela,

"The Specious Present: A Neurophenomenology of Time Consciousness" in Petitot, Varela, Pacoud and Roy eds.: Naturalizing Phenomenology: Issues in Contemporary Phenomenology and Cognitive Science (Cambridge: MIT, 1999) pp.266-315. An idea reader of this text would know the Varela piece and see in what is now being read a set of threads leading away from it.

[4] See Claude Lefort, "Le sens de l'orientation" in R. Barbaras, ed.: Merleau-Ponty: Notes de cours sur "L'origine de la géometrie" de Husserl (Paris: PUF, 1998) and R. Barbaras, "The Movement of the Living as the Originary Foundation of Perceptual Intentionality" in Petitot Varela et al. Naturalizing Phenomenology pp. 525-538.

$[5] \square$ W. Heisenberg, "Über den anschaulichen Inhalt der quantentheoretischen Kinematik und Mechanik", Zeitschrift für Physik, 43 1927, pp. 172-198. English translation: J. A. Wheeler and H. Zurek, Quantum Theory and Measurement Princeton Univ. Press, 1983, pp. 62-84.

[6] Bernhardt Riemann, "On the Hypotheses which lie at the Bases of Geometry" (1859) in Nature vol. 8 no. 183-184 available at: www.maths.tcd.ie/pub/HistMath/People/Riemann/Geom/WKC...

[7] Paul Klee: Notebooks v. 2 (Woodstock NY: Overlook Hardcover Press, 1992) p. 53 
[8] George Lakoff: Women Fire and Dangerous Things (Chicago: University of Chicago Press, 1990) p. 302. This brief reference to the cognitive frames interpolates elements from the section "Conceptual Frames" found here: http://cogweb.ucla.edu/CogSci/Lakoff.html.

[9] See Brain and Behavioral Science vol. 31 no. 5 (October 2008) for a debate about this question. $[10]$ Of particular interest in cognitive linguistics is the resultant intertwining of language and vision. $[11]$ Here one has a version of the separation from necessity that Pierre Bourdieu argued was characteristic of bourgeois socio-cultural stratification.

[12] The definition of attractor is where the intertwining of visual and linguistic is at its most interesting: see the work on "medial geometries" by Benjamin Kimia "On the Role of Medial Geometry in Human Vision" in Journal of Physiology (Paris) no. 97 (2003) pp. 155-190. At the same time, it is in the notion of attractor that the circularity of work in categorization or grouping is at its most evident. ${ }^{[13]}$ For a comprehensive overview elaborated from a viewpoint deeply influenced by Chomsky, see Ray Jackendoff, "Linguistics in Cognitive Science: The State of the Art" in The Linguistic Review no. 24 (2007) pp. 347-401.

[14] Vittorio Gallese and George Lakoff, "The Brain's Concepts: The Role of the Sensory-Motor System in Conceptual Knowledge" in Cognitive Neuropsychology vol. 22 nos. 3 \& 4 (2005) p. 456.

$[15]$ This point is a miniature version of a broader claim concerning the tendency to naturalize frame assumptions. For a detailed analysis of this in the context of thinking and experimentation on biological systems, see Henri Atlan: From Enlightenment to Enlightenment (Albany: Stat University of NY Press, 1993). See also Atlan, "Creativity in Nature and in the Mind: Novelty in Biology and in the Biologist's Brain" in SubStance vol. 19 no. 2/3 (1990) pp. 55-71

[16] Steven Rosen, "Quantum Gravity and Phenomenological Philosophy" in Foundations of Physics no. 38 (2008) p. 572.

[17] Timothy van Gelder and Robert Port, "It's About Time: An Overview of the Dynamical Approach to Cognition" in van Gelder and Port, eds.: Mind as Motion: Explorations in the Dynamics of Cognition (Cambridge: MIT, 1995) p. 11.

[18] See Francesco Varela, Evan Thompson and Eleanor Rosh: The Embodied Mind: Cognitive Science and Human Experience (Cambridge: MIT, 1991). Varela and Maturana seem to hover on the horizon for this type of work, see Shoji Nagatake and Satoru Hirose, "Phenomenology and the Third Generation of Cognitive Science: Toward a Cognitive Phenomenology of the Body" in Human Studies no. 30 (September 2007) pp. 219-232 and Erik Rietveld, "The Skillful Body as Concernful System of Possible Actions: Phenomena and Neurodynamics" in Theory and Psychology vol. 18 no. 3 (2008) pp. 341-363

[19] Lawrence Barsalou: "Ideals, Central Tendency and Frequency of Instantiation as Determinants of Graded Structure in Categories" in The Journal of Experimental Psychology: Learning, Memory and Cognition vol. 11 no. 4 (October 1985) pp. 629-654. A broader survey of literature in this area which outlines the conclusions developed in this paragraph is Gregory Murphy and Douglas Medin, "The Role of Theories in Conceptual Coherence" in Psychology Review vol. 92 no. 3 (July 1985) pp. 289-316. [20] I refer to 3 main texts by Petitot here: "Morphodynamics and Attractor Syntax: Visual Perception and Cognitive Grammar" in Port and van Gelder, eds. Mind as Motion op. cit; Petitot and Doursat, "Dynamical Systems an Cognitive Lingistics: Toward and Active Morphodynamical Semantics" in Neural Networks no. 18 (2005) pp. 628-638; Doursat and Petitot. "Bridging the Gap: A Morphodynamical Model of Spatial Categories" in Proceedings of the International Joint Conference on Neural Networks, Montreal July 31-August 4, 2005. My treatment of Petitot is more an advertisement for it which poses the question of scale and should not be taken as a systemic critique or as an excuse not to engage with his work, which is quite complex and very interesting. [21] As this is a précis of research directions, I think my task is complete if you, reader, are interested enough by this to investigate further.

[22] Curtis Roads, "The Perception of Microsound and its Musical Importance" in The Annals of the New York Academy of Science (New York Academy of Science no. 999 (2003) p. 279. See more generally Roads: Microsound (Cambridge: MIT, 2002) [23] Alfred Schutz: The Phenomenology of the Social World (Evanston: Northwestern UP, 1967) p. 47 [24] Yoram Louzon and Henri Atlan, "The Emergence of Goals in a Self-Organizing Network: A Nonmentalist Model of Intentional Actions" in Neural Networks no. 20 (2007) pp. 156-171. See also "JeanChristophe Sarrazin A. Cleeremans and P. Haggard, "How Do We Know What We Are Doing?: Time, Intention and Awareness of Action" in Consciousness and Cognition no. 17 (2008) pp. 602-615. 


\section{Nordicum-Mediterraneum}

[25] I only recently acquired Merleau-Ponty's Nature (Evanston: Northwestern UP, 2003) the lecture courses he did during the late 1950s at the Collège de France which introduced me to Whitehead's text. I am working my way through it, and look forward to getting back to this project.

[26] As an aside, there is a potentially quite interesting connection between Castoriadis' conception of time as auto-figuration and George Herbert Mead's The Philosophy of the Present (LaSalle Il: Open Court, 1932). See David Maines, Norman Sugrue and Michael Katovich, " The Sociological Import of G.H. Mead's Theory of the Past" in The American Sociological Review vol. 48 no. 2 (April, 1983) pp. 161-173. 